\title{
ПОЛИЦЕЙСКОЕ ПРАВО
}

С.Н. Бочаров

\author{
К ВОПРОСУ О ВЗАИМОДЕЙСТВИИ \\ ОРГАНОВ ВНУТРЕННИХ ДЕЛ \\ И ЧАСТНЫХ ОХРАННЫХ ОРГАНИЗАЦИЙ
}

$\mathrm{O}$ дним из путей реализации стоящих перед органами внутренних дел (далее - ОВД) задач обеспечения общественного порядка и общественной безопасности в условиях крупных городов является достижение высокой степени контроля полиции за поведением людей в жилых микрорайонах, на улицах и в других общественных местах, а также оперативное реагирование на любые, даже незначительные факты противоправных посягательств. Выражаясь образно, речь идет о необходимости создать эффект «постоянного присутствия» полицейского в публичных местах.

Вместе с тем, приходится констатировать, что ОВД в силу целого ряда обстоятельств как объективного, так и субъективного свойства самостоятельно претворить в жизнь данный прием повышения эффективности решения правоохранительных задач не в состоянии.

В этой связи возникает потребность задействовать дополнительные силы и средства извне. Однако степень сложности, ответственности и, не скроем опасности осуществления правовой охраны, требует серьезного взвешенного подхода в выборе участников такой совместной деятельности и ее организации.

На наш взгляд, реальный потенциал подобного участия присутствует именно у представителей частных охранных структур. Данный тезис объективно обусловлен рядом обстоятельств, а именно: значительная численность частных охранников; высокая степень организации их работы; сходность решаемых ими и органами внутренних дел задач в сфере обеспечения правопорядка; надлежащий профессиональный уровень работников ${ }^{1}$; достаточное материально-техни-

1 Около 40 \% частных охранников - это бывшие представители правоохранительных органов, обладающие знаниями, умениями и навыками правоохранительной деятельности. ческое обеспечение частных охранных организаций (далее - ЧОО); наличие правовых основ взаимодействия ЧОО и ОВД.

Современное состояние рассматриваемого взаимодействия в общем виде можно представить как дополняющие друг друга следующие его режимные варианты.

Постоянный режим взаимодействия, состоящий в основном в реализации информационно-правового и консультационно-методического сегмента.

Режим взаимодействия при функционировании ЧОО в частно-правовой сфере в процессе оказания услуг клиентам, состоящий в усилении открытого социального контроля поведения людей в публичных местах; в информировании ОВД о фактах, требующих правоохранительного вмешательства; обеспечении доказательственной базы при реализации ОВД административно процессуальных, уголовно процессуальных и юрисдикционных функций.

Режим взаимодействия при функционировании ЧОО в публично-правовой сфере, состоящий в содействии ОВД в решении конкретных правоохранительных задач по охране общественного порядка, обеспечению общественной безопасности, предупреждению, пресечению и раскрытию преступлений.

На наш взгляд наибольшую сложность в правовом и организационном аспектах представляет последний из выше перечисленных режимов взаимодействия. Нельзя не заметить, что его правовая регламентация в последнее время несколько улучшилась ${ }^{2}$, однако

\footnotetext{
2 Например, в развитие известного положения Федерального закона, предоставившего ЧОО право содействовать правоохранительным органам в обеспечении правопорядка, Постановлением Правительства РФ от 26 января 2012 г. № 10 «О внесении изменений в постановление Правительства Российской Федерации» от 14 августа 1992 г. № 587 / Утверждены Правила реализации данного права.
} 
идеальной ее назвать еще нельзя. Постановление Правительства РФ от 26.01.2012 № 10 установило лишь Правила предоставления ЧОО права содействовать правоохранительным органам в обеспечении правопорядка, но не Правила осуществления такого содействия, правовая характеристика которого продолжает оставаться проблематичной.

В указанном правительственном Постановлении обозначены возможные формы содействия ЧОО в обеспечении правопорядка, которые ОВД и без того достаточно хорошо известны и широко используются на практике.

В частности, это - участие в обеспечении правопорядка в местах проведения массовых мероприятий; содействие в вызове дежурных служб в случае обращения граждан к охранникам с просьбой о помощи; содействие в выявлении лиц, объявленных в розыск; незамедлительное информирование правоохранительных органов о ставших известными нарушениях общественного порядка, готовящихся, совершаемых и совершенных правонарушениях и преступлениях; организация совместных патрулей, в том числе с использованием транспортных средств ЧОО; предоставление используемых на охраняемых объектах технических средств охраны, средств аудио- и видео наблюдения для использования их в целях обеспечения общественной безопасности.

В то же время механизм реализации перечисленных форм содействия, а также юридические полномочия охранников, гарантии их правовой защиты продолжают оставаться нормативно неопределенными.

Действующее законодательство устанавливает вполне конкретные рамки правового статуса частных охранников. Они обладают некоторыми правами по применению специальных средств и огнестрельного оружия при защите от противоправных посягательств охраняемого имущества, жизни, здоровья охраняемых граждан и отражении нападения, угрожающего их собственной жизни и здоровью. Кроме того, при обеспечении внутриобъектового и пропускного режимов в пределах объекта охраны они уполномочены требовать от персонала и посетителей этих объектов соблюдения установленных правил поведения. Им также предоставлено право задержать на месте правонарушения для незамедлительной передачи в ОВД лиц, незаконно посягнувших на охраняемое имущество.

Таким образом, получается, что требовать прекращения противоправного поведения, проверять документы у граждан, изымать у них предметы, используемые при совершении правонарушения; доставлять указанных лиц в ОВД, применять физическую силу для пресечения нарушения и последующего доставления нарушителей, если это связано именно с охраной общественного порядка и обеспечением безопасности, тем более за пределами объекта охраны, частные охранники права не имеют.

Более того, действующее уголовное законодательство (ст. 203 УК РФ) за совершение подобных действий при определенных условиях предусматривает для охранников наступление уголовной ответственности.

Итак, частных охранников, не наделенных государством специальными полномочиями за пределами отношений, связанных с выполнением договорных обязательств ЧОО перед клиентами, следует рассматривать как обыкновенных граждан, для которых правовыми гарантиями защиты при вмешательстве в ситуацию, связанную с посягательством на общественный порядок, личную и общественную безопасность, выступают нормы административного и уголовного законодательства, регулирующие обстоятельства необходимой обороны, крайней необходимости и пр.

В то же время жизненные реалии таковы, что частные охранники привлекаются ОВД к обеспечению правопорядка в населенных пунктах посредством патрулирования публичных мест, при проведении массовых мероприятий, ликвидации последствий различных чрезвычайных обстоятельств. В данной связи представляется крайне важным изыскать законные пути, способные хотя бы в некоторой степени компенсировать отсутствие необходимых полномочий у работников ЧОО при выполнении указанных функций. Для этого необходимо выработать механизм реализации имеющихся на сегодняшний день правовых норм, допускающих подобное участие, сопровождаемое возможностью вынужденно применять охранниками принуждение для выявления и предупреждения правонарушений, пресечения противоправного поведения, обеспечения неотвратимости ответственности нарушителей, если конечно охранники не являются статистами при выполняющих свои профессиональные обязанности сотрудниках полиции.

Следует заметить, что всего несколько лет назад правовая ситуация была совершенно иной. Например, ст. 193, действовавшего ранее УК РСФСР, выступала правовой гарантией для любого гражданина, в связи с его участием в предупреждении, пресечении не только преступления, но и антиобщественного поступка. Кроме того, в свое время Указ Президиума Верховного Совета СССР «Об усилении ответственности за хулиганство» оценивал действия, направленные на пресечение преступления и задержание преступника, как правомерные и не влекущие наступление уголовной или иной ответственности. 
Однако отмена указанных нормативных актов на сегодняшний день требует определения конкретного алгоритма поведения охранников в заданных юридических условиях.

Представляется, что ситуация с участием частных охранников по предупреждению и пресечению противоправных посягательств на общественный порядок при содействии правоохранительным органам за пределами объектов охраны могла бы развиваться по следующей схеме.

1. Прежде всего, органу власти субъекта России, органу местного самоуправления либо администрации объекта и т.п., на территории которых частные охранники участвуют в обеспечении правопорядка, необходимо определить соответствующие правила поведения для лиц, находящихся в конкретных публичных местах.

2. Содержание таких правил поведения необходимо оформить изданием соответствующего официального письменного решения.

3. Обеспечить доступность для граждан указанных решений посредством их публичной демонстрации (плакаты, щиты), выдачи охранникам брошюрованных вариантов таких правил и т.п.
4. Установив факт нарушения гражданином такого решения, охранник обращает его внимание на наличие и действие в данном месте конкретных правил поведения и необходимость их безусловного выполнения.

Если гражданин прекращает совершать противоправное деяние, то проблема решена. В случае же открытого игнорирования замечания охранника и продолжения гражданином попыток нарушить установленные правила поведения, содеянное им можно рассматривать как мелкое хулиганство либо самоуправство, позволяющие охраннику, пользуясь положениями законодательства о необходимой обороне и крайней необходимости, пресекать противоправное поведение и принимать меры, обеспечивающие последующее привлечение нарушителя к соответствующей юридической ответственности.

Думается, что подобный порядок действий частных охранников, участвующих в охране общественного порядка и обеспечении общественной безопасности, позволит повысить эффективность их роли в решении данных задач и избежать ненужных юридических проблем.

\section{Библиографический список:}

1. Аршинов А.Л. Взаимодействие органов внутренних дел с частными структурами безопасности в охране общественного порядка и борьбе с преступностью // Предупреждение преступности и обеспечение безопасности в городах. - М., 2001.

2. Абрамов В.С., Дорофеев И.Г., Зыков В.Н., Михина Т.В. Правовые основы предпринимательской безопасности. - М., 2003.

3. Амельчаков И.Ф., Белорусов В.Б. Частная детективная и охранная деятельность в России. - М., 2003.

4. Амельчаков И.Ф., Белорусов В.Б. Лицензионно-разрешительная деятельность органов внутренних дел. Тамбов, 2003.

\section{References (transliteration):}

1. Arshinov A.L. Vzaimodeystvie organov vnutrennikh del $\mathrm{s}$ chastnymi strukturami bezopasnosti $\mathrm{v}$ okhrane obshchestvennogo poryadka i bor'be s prestupnost'yu // Preduprezhdenie prestupnosti i obespechenie bezopasnosti v gorodakh. - M., 2001.

2. Abramov V.S., Dorofeev I.G., Zykov V.N., Mikhina T.V. Pravovye osnovy predprinimatel'skoy bezopasnosti. — M., 2003.

3. Amel'chakov I.F., Belorusov V.B. Chastnaya detektivnaya i okhrannaya deyatel'nost' v Rossii. — M., 2003.

4. Amel'chakov I.F., Belorusov V.B. Litsenzionno-razreshitel'naya deyatel'nost' organov vnutrennikh del. — Tambov, 2003. 